\title{
La cerámica de la Alta Edad Media en Cataluña (S. VIII-IX d. C.): el estado de la cuestión
}

\author{
Cristian Folch Iglesias *
}

\begin{abstract}
RESUMEN
Este texto pretende mostrar el estado de la investigación sobre las cerámicas de la alta edad media en Cataluña (Siglos VIII-IX d.C). Estas cerámicas presentan problemas en su estudio, pero con las últimas investigaciones sobre yacimientos de este periodo, hemos podido aislar diversas características comunes que permiten empezar a diferenciarlas.
\end{abstract}

PALABRAS CLAVE: alta edad media, cerámicas, Cataluña.

\section{INTRODUCCIÓN}

El objetivo de este texto es plantear el estado de la cuestión sobre la investigación de los contextos cerámicos del inicio de la alta edad media en Cataluña (Siglos VIII-IX d.C.) '. Estas cerámicas presentan una serie de características que permiten empezar a diferenciarlas y

\begin{abstract}
This paper shows the actual status about the early middle age ceramics investigation in Catalonia (Centuries VIII-IX b.C). This ceramics has more problems in their study but with the results of the last investigations about the early middle age sites in Catalonia we have established some common features for this ceramics.
\end{abstract}

KEY WORDS: early middle age, ceramics, Catalonia.

proponer aspectos comunes con los que poder ofrecer cronologías más claras para los yacimientos de este período. El gran auge de la investigación en arqueología medieval en Cataluña, en los últimos años, nos ha permitido reunir una serie de datos de diversos yacimientos arqueológicos, con cronologías bastante claras que se sitúan en los siglos VIII-IX². Estos nos

\footnotetext{
* Arqueólogo, C/Felipe II Nº $272^{\circ}-2^{a}$ 08917, Badalona (Barcelona). Folch72@hotmail.com. Colaborador en la UAB.

I Queremos agradecer a Joan Llinàs, a Jordi Roig, a Francesc Busquets, a Montserrat Mataró, a Jordi Tura, a Josep Maria Benet, a Josep Maria Cau i a Josep García, su gentileza al dejarnos publicar las láminas de los dibujos de cerámica que acompañan al texto.

2 La mayoría de yacimientos citados en el texto corresponden a excavaciones recientes efectuadas con una metodología actual. Nos hemos centrado en un espacio de tiempo que abarca los siglos VIII-IX, desechando los yacimientos que presentan cerámicas espatuladas, un tipo de cerámica muy común en Cataluña, que parece que se puede empezar a fechar, para algunos casos concretos, desde finales del siglo IX, pero que se documenta más extensamente en el siglo $X$ y perdura hasta el XI. Los conceptos utilizados en el texto para describir los tipos de cocciones como reductora y oxidada son los que normalmente se utilizan. En Cataluña utilizamos el concepto óxidoreductora o mixta para describir las cerámicas que no presentan cocciones homogéneas en toda la pieza.
} 
ayudaran a acercarnos, un poco más, a la problemática que presentan estas cerámicas en Cataluña actualmente ${ }^{3}$.

En otras zonas de la Península lbérica, estudios sobre este período han abierto nuevas líneas de investigación, superando diversos condicionantes historiográficos y han dado a conocer unos contextos cerámicos que han permitido establecer cronologías bastante claras de estos yacimientos arqueológicos, como se ha hecho en Alicante y Murcia (GUTIERREZ, S. 1996).

En los casos en que hemos tenido acceso al material cerámico, el análisis se ha efectuado a partir de la observación a nivel macroscópico de los fragmentos cerámicos, con una clasificación siguiendo criterios tipológicos y cualitativos de las pastas (tipos de cocción, coloración, tratamiento de las superficies y decoraciones).

\section{LOS PRECEDENTES: LA CERÁMICA COMÚN DE LA ANTIGÜEDAD TARDÍA EN CATALUÑA (SIGLO VII d.C.)}

Últimamente el gran desarrollo de la investigación sobre la Antigüedad Tardía en Cataluña ha permitido estudiar un gran número de yacimientos arqueológicos con cronologías de los siglos $\mathrm{VI-VII}{ }^{4}$, muy adecuados para enfrentarnos a la problemática que presentan los contextos cerámicos de los siglos VIII-IX.

En el siglo VII la cerámica común romana deja de ser tan homogénea como en siglos anteriores, donde la producción estaba muy estandarizada y empieza a predominar la cerámica de cocción reductora (LLINAS, J. 1997). Así, para los contextos del siglo VII en Cataluña, la cerámica se caracteriza por tener una cocción oxidada (jarras y cuencos) y reductora (ollas y cazuelas). Esta convivencia de las cerámicas comunes oxidadas y reductoras se va decantando hacia estas últimas, a medida que avanzamos en el tiempo. En yacimientos con cronologías del siglo VII como Vilauba (Camós), destacan sobre todo las ollas, igual que en la Ciutadella (Roses), en la Solana (Cubelles), en Aiguacuit (Terrassa), en Vilaclara (Castellfollit del Boix) y en la Carretera (St Martí d'Empúries). En estos yacimientos aun hay semejanzas con las producciones romanas de cerámica común de los siglos V-VI. Uno de los aspectos que permite diferenciar "la romanidad" de estas producciones son los bordes biselados o con encaje para tapadera. Este distintivo de las cerámicas romanas comunes en la Antigüedad Tardía se ha estudiado en comarcas como el Valles Occidental y Oriental (Barcelona) (COLL, J.M y ROIG, J 1997-2000).

Para los contextos del siglo VII podemos dividir las cerámicas comunes en dos grupos:

I Cerámica reductora. Tipologicamente representada por ollas con los bordes biselados o con encaje para tapaderas, ollas con los bordes redondeados y cazuelas, estas piezas que presentan pastas torneadas y compactas y pastas bastas y frágiles, tienen coloraciones negras, grises y marrones, con ejemplos documentados en los yacimientos

\footnotetext{
3 En una reciente síntesis sobre las cerámicas de los siglos VII-X en la provincia de Barcelona, casi no aparecen contextos de los siglos VIII-IX, lo que plantea muchas dudas sobre este material cerámico. LÓPEZ, Alberto et alii (2003): "Cerámica tardorromana y altomedieval en la provincia de Barcelona. Siglos VII-X". CABALLERO, Luis; MATEOS, Pedro y RETUERCE, Manuel (edts.) (2003). Cerámica tardorromanas y altomedievales en la Península Ibérica. Anejos de AespA XXVIII, Mérida, 4I-65 Algunos contextos cerámicos que han aparecido recientemente y una revisión de otros más antiguos nos han hecho aislar diversas características que pensamos que aportan nuevos datos que permiten entender, de una manera más clara, la evolución de la cerámicas en los siglos VIII-IX. En el estudio de estos dos siglos la cerámica islámica en Cataluña siempre se ha obviado, por la supuesta presencia testimonial, sobretodo en Cataluña Vella, y, no lo olvidemos, actualmente es un referente a la hora de estudiar estos dos siglos en toda la Península Ibérica..

4 En Cataluña tenemos ejemplos como: el Hort d'en Bach (Maçanet de la Selva), Pla de Palol (Platja d'Aro), Vilauba (Camós), La Vila dels Atmetllers (Tossa de Mar), St Julià de Ramis, La Ciutadella (Roses), La Carretera (St Martí d' Empúries), El carrer del museu N I (Empúries), Vilaclara (Castellfollit del Boix), Els Maiols (Cerdanyola), La Solana (Cubelles), La plaça del Rei (Barcelona), l'Església Vella de Sant Menna (Sentmenat del Vallès) y Sant Vicenç de Rus (Castellar de N'Hug).
} 
de La Carretera (St Martí d’ Empúries), La Ciutadella (Roses), Vilauba (Camós), Aiguacuit (Terrassa), Vilaclara (Castellfollit del Boix) y la Solana (Cubelles).

2 Cerámica oxidada. Estas cerámicas se caracterizan por presentar formas como jarras $y$ cuencos y unas pastas depuradas y compactas y por tener coloraciones naranjas, ocres o rosadas. Están documentadas en los yacimientos de la Carretera, (St Martí d' Empúries), La Solana (Cubelles), Vilaclara (Castellfollit del Boix) y la Ciutadella (Roses).

Los últimos estudios sobre Terra Sigillatta Africana D y ánforas, en contextos del siglo VII en Cataluña (LLINAS, J.1997), muestran una disminución de estos materiales cerámicos en el registro arqueológico. Parece ser que la desaparición de estas cerámicas de importación debería producirse a finales del siglo VII, aspecto que nos muestra, con claridad, que en un momento impreciso entre finales del siglo VII y inicios del siglo VIII las cerámicas de importación van desapareciendo del registro. Podemos encontrar ejemplos en yacimientos como Vilaclara (Castellfollit del Boix), Mas de Catxorro (Benifallet), Aiguacuit (Terrassa) y el caso excepcional de Bovalar (Seròs) en el que se documentaron una serie de monedas de Ákhila, fechadas en el primer cuarto del siglo VIII, donde dichas cerámicas de importación no aparecen en este registro del momento de abandono.

\section{ALGUNOS CONTEXTOS CERÁMICOS DE LA ALTA EDAD MEDIA EN CATALUÑA (SIGLOS VIII-IX d.C.)}

\section{La Devesa (Besalú)}

Las excavaciones arqueológicas han permitido documentar abundantes restos arqueológicos en gran parte del subsuelo del casco antiguo de Besalú y han mostrado la importante continuidad de ocupación que ha tenido esta población a lo largo de los siglos. Las excavaciones se han realizado en la calle Major, Talla- ferro, del Portalet y en la zona conocida como la Devesa. En la fase que corresponde a la alta edad media se documentaron diversos silos amortizados por una torre de los siglos $\mathrm{X}-\mathrm{XI}$.

El campo de silos: Las estructuras se localizan en el sector más noroccidental de la Devesa, justo cerca de una torre superpuesta. Del material arqueológico, que se documentó en el interior de los silos, destaca la cerámica. Tipológicamente las piezas corresponden a utensilios de medida pequeña, de uso doméstico. La mayor parte de las formas recuperadas corresponden a ollas, se caracterizan por tener el borde exvasado, más o menos redondeado, cuerpo globular y base plana. Las jarras presentan similitudes tipológicas, pero conservan un encaje en el borde y las cazuelas tienen el borde abierto, algunas con el borde biselado y la base plana. Se han diferenciado tres tipos de cocción; reductora, mixta y oxidada. Las pastas presentan una importante cantidad de desgrasante, hay algunos ejemplos de acabados con acanaladuras que se encuentran en el cuerpo de las piezas (BUSQUETS, Fy FÀBREGAS, M 1998).

\section{La Torre Mora (St Feliu de Buixalleu)}

La torre esta construida con bloques grandes ligeramente desbastados por las caras vistas, de medida variable. La construcción combina los grandes bloques unidos con mortero de cal, con piedras más pequeñas también unidas con el mismo mortero. La torre tiene un diámetro exterior de 9'5 metros y un diámetro interior de 5'70 metros.

Los materiales cerámicos forman parte de un conjunto de piezas muy homogéneo en cocción oxidada y reductora y el desgrasante es de cuarzo y mica. Algunas piezas presentan diferentes tonalidades de color que van del negro al naranja. Se trata de pastas blandas y duras, algunas piezas están muy bien realizadas (pastas duras, bien depuradas, paredes delgadas) y otras de aspecto más basto (pastas blandas, poco depuradas y paredes gruesas). En lo que a tipología se refiere, los bordes son mayoritariamente exvasados, redondeados o biselados y de perfil sinuoso y las bases son siempre planas. Cabe destacar una pieza en cocción 
reductora, sin cuello y con el borde ligeramente grueso, decorada con acanaladuras. En general las piezas recuperadas son ollas de forma más o menos globular y de base plana. La cronología de estas piezas es poco precisa pero recuerda algunos materiales que cronológicamente se sitúan en los siglos VIII-IX (FONT, G et alii 1996 y 2000$)^{5}$.

\section{Bovalar (Seròs)}

Se trata de un poblado de época visigoda, formado por diversas habitaciones, que se desarrolla alrededor de una iglesia. Un incendio significó la destrucción del poblado que ofreció un terminus post quem de primer cuarto del siglo VIII con la presencia de monedas de Ákhila. En algunas habitaciones se pudo documentar un gran número de copas de cristal y además se encontraron indicios de contenedores de madera. Se han encontrado pocos objetos metálicos, a excepción de diversas piezas destinadas a uso litúrgico, encontradas, exclusivamente, en la iglesia (PALOL, P 1989).

El material cerámico es muy homogéneo. Formado por ollas con el borde biselado, algunas jarras y grandes contenedores. Hay una coexistencia entre las cocciones reductora, oxidada y mixta, que proporcionan a las piezas coloraciones que van del negro al marrón (CAU, J.M et alii 1997).

\section{Aiguacuït (Terrassa)}

Se han identificado dos estructuras de vertedero, un conjunto de catorce silos, restos de una cabaña semisubterranea y diversos recortes, que ocuparían la parte noroeste de una villa romana abandonada en el siglo $\mathrm{VI} 6$.
Los estratos de relleno de los silos y estructuras han proporcionado unos contextos cerámicos unitarios, que se caracterizan por su homogeneidad y similitud, representados básicamente por producciones reductoras y óxido reductoras.

La forma más representada es la olla, con el cuerpo cónico, alargado y esférico, con la base convexa, el borde exvasado ${ }^{7}$, redondeado o biselado. Las cerámicas son torneadas o hechas a mano, de cocción irregular, que dan coloraciones a las piezas grises, negras y marrones. Los acabados de las superficies son bastos (COLL, J.M et alii 1997 y 2000).

\section{Mas de Catxorro (Benifallet)}

Las obras de acondicionamiento de la carretera $\mathrm{N}-230$ en el trayecto Mora-Tortosa y la construcción del Pont Llagoter sobre el rió Ebro, llevaron a la realización de diversas campañas arqueológicas en la finca de Mas de Catxorro, situada en el termino municipal de Benifallet (Baix Ebre).

La fase estudiada en este trabajo corresponde al momento final de la ocupación del yacimiento, situada en el siglo VIII. Los restos estaban formados por tres habitaciones, un deposito rectangular de opus signinum, una estructura cuadrangular construida con piedras y sustentada por dos muros en ángulo, una cubeta circular que aparece rodeada de diversos agujeros de poste excavados en las arcillas y cuatro silos.

El material cerámico, recuperado en esta fase, lo forman un conjunto de cerámicas comunes de tradición visigoda. La pasta es frágil y

\footnotetext{
5 Esta torre ha sido identificada como islámica, contruida en el momento de la conquista, asociada a un topónimo concreto que en Cataluña recibe la denominación de Far. Para las últimas investigaciones sobre toponímia islámica en Cataluña ver: Martí, R. (2003): "La defensa del territori durant la transició medieval." I Congrés: els Castells medievals a l' occident de la Mediterània. Arbúcies, 89- I I4.

6 En la comarca del Vallés Occidental (Barcelona), el yacimiento de l'Aiguacuït (Terrassa) es una villa romana abandonada en el siglo $\mathrm{VI}$. El sector noroccidental se reocupa en el siglo VIII con una cabaña y silos, que muestran los pocos restos que dejan estos asentamientos de la alta edad media en Cataluña. Este yacimiento ha sido identificado con el topónimo de Palacio Fracto, que aparece en la documentación medieval de Terrassa, y se ha relacionado con un tipo de topónimo originado a partir de la conquista islámica, en este caso, del noreste de la Península Ibérica. MARTÍ, R y SELMA, S (2000): "Fortificaciones y toponímia Omeya en el este de al-Andalus". Simposio Internacional Sobre Castelos, Palmela 2000. FOLCH, Cristian (2003): "Estratègies de conquesta i ocupació islàmica del nord-est de Catalunya", Quaderns de la Selva No |4. Consell Comarcal de la Selva, I39-15.
} 
poco depurada, con abundante desgrasante, las formas se reducen a ollas con el borde redondeado o biselado y jarras con asas. Los paralelos más cercanos se sitúan en el nivel de destrucción del poblado de Bovalar (Seròs) fechado en el primer cuarto del siglo VIII (BENET, J.M et alii 199|-92).

\section{Pla d'Almatà (Balaguer)}

Las excavaciones se han realizado entre los años 1983-90 en el lugar conocido como el Pla de Almatá, un asentamiento islámico de primera época. En diversas campañas solo se han podido documentar pocos restos atribuibles a cronologías de los siglos VIII-IX, estos corresponden a algunas habitaciones con hogares $y$ pavimentos relacionados. Se trataría de un recinto amurallado con una ciudad-campamento vinculada a las grandes campañas ultrapirenaicas, que el estado Omeia desarrolla durante la primera mitad del siglo VIII.

La cerámica esta formada en su mayoría por ollas en cocción reductora con el borde redondeado, con asas y de forma globular, algunas cazuelas y por cerámica en cocción oxidada que corresponde a otra cazuela y diversas piezas con vidriado amarillo. Las decoraciones son mayoritariamente bandas incisas formando ondulaciones (CAU, J.M et alii 1997 y GARCÍA, J.E. et alii 1998).

\section{Arxiu Administratiu (Barcelona)}

El yacimiento esta situado en el solar del antiguo Archivo Administrativo de la ciudad de Barcelona y esta delimitado por la muralla romana, a la altura de la calle Sotstinent Navarro y la bajada Caçador y la calle Bisbe Caçador. La construcción de una nueva sede del archivo, hizo necesario un proyecto de excavación arqueológica. El yacimiento presenta una secuencia cronológica desde los siglos IV-V a los siglos IX-X. En este caso nos interesan las fases III y IV fechadas en los siglos VIII y IX. Los restos que corresponden a la fase III están formados por diversas modificaciones documentadas en una domus bajoimperial precedente, en la cual se documenta la construcción de un muro y el arrasamiento de las paredes de las antiguas instala- ciones termales, resultando una habitación de forma rectangular. La fase IV esta formada por una compartimentación de la habitación documentada en la fase anterior, con la construcción de una pared perpendicular a las existentes, con la que se relacionan pavimentos y un hogar.

La cerámica de la fase III está formada por piezas vidriadas y comunes atribuibles a producciones islámicas de finales del siglo VIII, bien fechadas con un dirham de plata del 150 de la Hégira (767-776) dentro del gobierno del emir Abd al-Rahmân I. La cerámica vidriada esta formada por jarras, zafas y una forma cerrada, las pastas en cocción oxidante y con vidriados, verdes, amarillos, con óxido de hierro o manganeso y con engalba blanca. La cerámica común esta formada por piezas en cocción reductora y mixta con una tipología representada por ollas, cazuelas, cuencos y diversas formas cerradas. La cerámica de la fase IV, fechada en el siglo IX, presenta muchas similitudes con la de la fase anterior, únicamente se observa una reducción tipológica que estaría formada por ollas, cazuelas y cuencos (GARCÍA, J.E et alii 2003).

\section{Peralada}

La fase III de este yacimiento, fechada en los siglos VIII-IX, corresponde a los restos de una fortificación carolingia, de una necrópolis y de unas habitaciones.

La fortificación: se descubrió el muro perimetral este y el sur de una construcción de planta cuadrangular. El muro perimetral, de la parte oeste se excavó en una longitud de 15 metros. Tenía un grosor de dos metros y se conservaba en una altura entre 1,20 y 1,90 metros. En el extremo sur este muro giraba hacia el oeste, cerca de 13 metros.

La técnica constructiva utilizada es de una doble pared con relleno interno, hecha con piedras de río de dimensiones pequeñas y medianas unidas con barro. Tenia unos cimientos de 1,20-1,25 metros de potencia y una pared vista que presentaba un paramento externo hecho con hiladas de piedras y losas mínimamente repicadas. 
La necrópolis: la excavación en el convento de Sant Bartomeu permitió documentar veinticuatro tumbas. La tipología de la cuales se resume en tres tipos: tumbas de bañera, con cantos de río y con resalte antropomorfo. En el primer caso las tumbas presentan forma de bañera con la cabecera y los pies redondeados. Los materiales más utilizados son las piedras de río y las losas de piedra. En el segundo caso las tumbas presentan una sepultura formada por un círculo de cantos de río que enmarcan al difunto y las terceras un resalte antropomorfo. En todos los casos este resalte se hace con dos piedras que enmarcan el cráneo.

Habitaciones: en la plaza Ramon Muntaner se localizaron los restos de diversas habitaciones que corresponden a la primera ocupación medieval de Peralada. Los restos están formados por dos silos, los restos de un pavimento y diversos muros unidos en seco que formarían las habitaciones.

Entre los materiales cerámicos recuperados en Peralada destacan los típicos recipientes culinarios (ollas y jarras) de cerámica común reductora y mixta, producida a torno lento o a mano con pastas frágiles, poco depuradas, de un repertorio formal muy pobre (LLINAS, J. et alii 1999).

\section{Can Pelet Ferrer (Llagostera)}

Este yacimiento se localizó en una intervención de urgencia efectuada en el tramo de la carretera Gl-68l que va de Llagostera a Tossa de Mar. El seguimiento de las obras en la zona del mas de Can Pelet Ferrer, que quedaba afectado, puso al descubierto un total de 29 estructuras. Estas estaban formadas por fosas de planta circular, excavadas en la roca, y pequeños agujeros de poste asociados. De las fosas excavadas, 18 han proporcionado materiales arqueológicos, se trata de cerámica, fauna, metales y algunos elementos líticos. Cronoló- gicamente podemos decir que el hecho de encontrar una moneda de Luis el Piadoso (814840) localizada en la fosa I, nos acerca a un contexto situado entre los siglos VIII-IX.

La cerámica es, en general, blanda y poco depurada con desgrasante de cuarzo de gran tamaño. Las formas son típicas del repertorio de cerámica alto medieval; ollas y jarras de perfil en ese y fondo plano y cazuelas. De las siete piezas mejor conservadas, cinco son ollas globulares, con el borde ligeramente grueso y remarcado y fondo plano y tres de ellas tienen asas, además se documentó una cazuela pequeña. También se ha localizado en otra fosa un mortero que se inspira claramente en morteros tardoromanos. Es una pieza de paredes rectas y abiertas y fondo plano (PALOMO, $V$ et alii 2000-2003).

\section{Montclús ${ }^{8}$ (Sta. Maria de Merlès)}

El Vilar de Montclús aparece en la documentación medieval el año 893, en el acta de consagración de la iglesia de Santa Maria de Merlès.

La excavación arqueológica en este yacimiento nos ha permitido documentar, por una lado una edificación de forma rectangular, delimitada por tres muros con piedras de medida grande y mediana desbastadas por las caras vistas y unidas en seco y por otro lado se ha documentado otra edificación, más pequeña que la anterior y situada a su lado, también de forma rectangular, formada por tres muros de piedras pequeñas y medianas, sin desbastar y unidas en seco. Se ha documentado diversos agujeros de poste excavados en la roca que formarían parte de estructuras subsidiarias construidas con materiales perecederos. El material arqueológico documentado esta formado por cerámica, algunos objetos de hierro y una muela de molino manual.

\footnotetext{
8 Este yacimiento ha permitido estudiar un asentamiento del inicio de la alta edad media (siglo IX) sin ninguna ocupación anterior ni posterior. En la excavación hemos documentado cerámicas, objetos de hierro y una muela de molino manual. FOLCH, Cristian; MARTÍ, Ramon (en prensa): "Un edifici del segle IX del Vilar de Montclús (Sta Maria de Merlès, Berguedà)", Jornades de Paleonto-
} logia i Arqueologia de les comarques de Barcelona. St Boi del Llobregat 2003. 
La cerámica es de cocción reductora y óxido reductora, de pastas poco consistentes, con abundante desgrasante de cuarzo, con coloraciones negras, grises y marrones, atribuibles a producciones del siglo IX. El repertorio formal es breve, formado en su mayoría, por ollas de perfil en ese, ollas globulares, con el borde redondeado y el fondo plano o convexo, por jarras con el borde redondeado y una cazuela pequeña de paredes abiertas y el fondo plano. La decoración es casi inexistente, solo podemos destacar algunas piezas decoradas con líneas incisas (FOLCH, C y MARTÍ, R 2003 y FOLCH, C 2005).

\section{LA EVOLUCIÓN DE LOS CONTEXTOS CERÁMICOS (SIGLOS VIII-IX d.C.) EN CATALUÑA}

Después de esta breve recopilación de yacimientos, con el estado actual de la investigación arqueológica en Cataluña, podemos plantear que estos contextos cerámicos de los siglos VIII-IX, que han resultado muy problemáticos, ya permiten establecer cronologías más claras de los yacimientos donde aparecen.

En estas cerámicas cabría diferenciar tres momentos cronológicos diferentes: primero los yacimientos que se pueden situar en el inicio del siglo VIII, pero que en algunos casos pueden perdurar a lo largo de todo este siglo, como los casos de Aiguacuït (Terrassa), Mas de Catxorrro (Benifallet), Bovalar (Seròs), la Torre Mora (Sant Feliu de Buixalleu) y la Devesa (Besalú). Segundo los yacimientos que se pueden fechar a finales del siglo VIII y en el siglo IX, como el caso del Arxiu Administratiu (Barcelona) y el Pla d'Almatà (Balaguer) y, tercero, los yacimientos que se pueden fechar en el siglo IX, como los casos de Peralada, Can Pelet Ferrer (Llagostera) y Montclús (Santa Maria de Merlès).

Para la cerámica del inicio del siglo VIII, pero que en algunos casos pueden perdurar a lo largo de este siglo, podemos establecer dos contextos culturales distintos: por un lado una serie de contextos cerámicos de época visigoda que luego se pueden seguir documen- tando en época islámica y por otro lado otros contextos de época islámica con características claras en algunos contextos islámicos del resto de la Península Ibérica. Los primeros se caracterizan por presentar cerámicas en cocción reductora y óxidoreductora y diversos paralelos formales entre ellos, a destacar las ollas con el borde biselado que encontramos en yacimientos como Mas de Catxorro (Figura 5, $n^{\circ}$ I, 3 y 4), en Bovalar (Figura 3, $n^{\circ}$ 5) y en Aiguacuït (Figura $4 n^{\circ} 4,5$ y 6), ollas con el borde redondeado que encontramos en Bovalar (Figura 3, $n^{\circ}||$ y |2) y en Aiguacuït (Figura $4 n^{\circ}$ I, 2, 3, 4, 5 y 6 ) y jarras con el borde redondeado y asas documentadas en Bovalar (Figura 3, no 1, 4, 6, 7, 8, 9 y I0), en Aiguacuït (Figura 4, n' 7 ) y en Mas de Catxorro (Figura $5, n^{\circ} 2$ ).

Los contextos de época islámica, en el siglo VIII, se caracterizan por la presencia de cerámicas comunes oxidadas, reductoras y óxidoreductoras. Para las oxidadas la tipología más representada son las jarras, que aparecen en la Torre Mora (Figura 2, $n^{\circ}$ 6) y en La Devesa (Figura I, no 15). Para las reductoras y óxidoreductoras podemos diferenciar dos tipos: la ollas con el borde redondeado o biselado que se encuentran en la Torre Mora (Figura 2, $n^{\circ} 1,3,4$ y 5 ) y en la Devesa (Figura I, $n^{\circ} 4$, $5,11,12,13$ y 14 ), en este yacimiento hay un ejemplar con acanaladuras (Figura I, $n^{\circ} \mathrm{I}$ ), y en La Torre Mora también hay un recipiente con el borde cerrado y decorado con acanaladuras (Figura 2, $n^{\circ} 2$ ). Estos dos contextos islámicos tienen paralelos en la provincia de Castellón, donde se ha excavado una torre islámica fechada en el siglo VIII con unas cerámicas similares, destacando algunos ejemplos oxidados y otros reductores y óxidoreductores decorados con acanaladuras. (MARTí, R y SELMA, S 1996-97). En la ciudad de Zaragoza también se han documentado cerámicas oxidadas y reductoras representadas por jarras y ollas decoradas con acanaladuras, fechadas en el siglo VIII (GALVE, P 1988), también en el yacimiento del Tolmo de Minateda han aparecido cerámicas similares decoradas con acanaladuras (GUTIÉRREZ, S 200 la), parecidas a las documentadas en Cataluña. 
La cerámica de época islámica, que se puede situar cronológicamente en el final del siglo VIII y el siglo IX, esta representada en las fases III y IV del yacimiento del Archivo Administrativo (Barcelona). Este contexto islámico esta formado por cerámicas vidriadas, pintadas y comunes, como las ollas con el borde biselado (Figura 6, $n^{\circ} 3,4,5,6,7$ y 8 ), jarras con el borde biselado, (Figura 6, $n^{\circ} \mid$ y $\mid 5$ ) y cazuelas (Figura 6 , $n^{\circ} 18,19,20$ y 22). Para esta misma cronología, cabe destacar el yacimiento islámico del Pla d'Almatá (Balaguer). En éste se ha documentado un contexto formado por cerámicas en cocción reductora, representadas por ollas con el borde biselado (Figura 10, $n^{\circ} 2$ y 3 ) y por cazuelas (Figura I0, $n^{\circ} \mathrm{I}$ ), por cerámica oxidada, formada por otra cazuela (Figura 10, $\mathrm{n}^{\circ}$ 7) y diversas cerámicas vidriadas en amarillo (Figura 10, no 4 y 6). Estas cerámicas aparecen, normalmente, en contextos islámicos del siglo IX del resto de la Península Ibérica, como en el yacimiento de Cercadilla (Córdoba) (FUERTES, M.C. 2000) y en el Tolmo de Minateda (Albacete) (GUTIÉRREZ, S $200 \mathrm{lb}$ ).

La cerámica que se puede situar en el siglo IX está bien representada en yacimientos de época carolingia. Se documentan mayoritariamente ollas con el borde redondeado de perfil en ese, como los casos de Peralada (Figura $9 n^{\circ} 2$ y 5 ), Can Pelet Ferrer (Figura 8, no I, 2, y 3 ) y Montclús (Figura 7 no 1, 7, 8 y 9), ollas con el borde redondeado de perfil globular en Montclús (Figura 7, n 3, 4 y 5) y en Peralada (Figura 9, $n^{\circ}$ I), ollas con el borde engrosado, con o sin asas, documentadas en Can Pelet Ferrer (Figura $8 n^{\circ} 5$ y 7 ), cazuelas con el borde redondeado en Can Pelet Ferrer (Figura $8, n^{\circ} 6$ y 8 ) y en Montclús (Figura $7, n^{\circ}$ 6) y jarras con el borde redondeado que encontramos en Peralada (Figura 9, no 3 y 4 ) y en Montclús.

\section{CONCLUSIONES}

Después de este pequeño análisis, podemos plantear diversas características comunes para estas producciones de cerámica de los siglos VIII-IX. Los contextos cerámicos islámicos, en el inicio del siglo VIII, pero que pueden perdurar a lo largo de este siglo, presentes en los yacimientos de la Devesa (Besalú) y la Torre Mora (Arbúcies), solo presentan cerámicas comunes, en cocción oxidada, reductora y óxidoreductora, con unas pastas, por un lado depuradas y compactas, donde la forma más característica seria la jarra y por otro unas pastas poco depuradas y con abundante desgrasante, donde las formas más características serían las ollas con el borde biselado, una característica de la cerámica de la Antigüedad Tardía, las ollas con el borde redondeado y las cazuelas. Para esta cronología cabe destacar la decoración con acanaladuras que parece que es un distintivo de la cerámica islámica de primera época de conquista, ya que se documentan, para esta misma cronología, en Castellón, en Zaragoza, en Murcia y en Alicante. A finales del siglo VIII se documentan en Cataluña las primeras cerámicas vidriadas en cocción oxidada y con pastas compactas, con vidriado en amarillo o en verde, decoradas con oxido de hierro, de manganeso o con engalba blanca, junto con cerámicas comunes, que están presentes en los yacimientos del Arxiu Administratiu (Barcelona) y el Pla d'Almatá (Balaguer). En estos dos casos queremos destacar que se trata de dos yacimientos relevantes durante la conquista islámica, en el primer caso la antigua ciudad episcopal de Barcelona y en el segundo una nueva ciudad-campamento. Para esta cronología de final del siglo VIII, de momento, no ha aparecido ningún contexto similar formado por cerámicas vidriadas en el ámbito rural. Esto puede deberse al hecho de que Barcelona y Balaguer reciban cerámicas de importación directamente del sur de al-Andalus o de Damasco o de otras zonas de oriente. En el siglo IX estas cerámicas seguirán apareciendo en el registro, junto con las cerámicas comunes, en las zonas de Cataluña que quedaran bajo influencia islámica como Lleida y Tortosa. El repertorio formal en este periodo es más variado en cuanto a los bordes y medidas de las piezas, aunque las formas mayoritarias continúan siendo las ollas, las cazuelas y las jarras.

La cerámica de época visigoda y carolingia, en estos dos siglos, se caracteriza por la variedad de cocciones, desde la reductora más perfecta que da a las piezas coloraciones grises y negras, a cocciones óxidoreductoras que dan 
a las piezas coloraciones marrones. Otro aspecto por el que destacan es por sus pastas, por un lado un grupo de cerámicas con pastas compactas y depuradas y por el otro poco compactas y de aspecto basto y frágil con gran cantidad de desgrasante. El repertorio formal en el siglo VIII quedará reducido a las ollas con el borde biselado, una característica de la cerámica común de la Antigüedad Tardía que aun perdura, a las ollas con el borde redondeado y a las jarras con o sin asas, con ejemplos documentados en los yacimientos de Bovalar (Serós), Aiguacuit (Terrassa) y Mas de Catxorro (Benifallet). Estas cerámicas siguen apareciendo en el registro en época islámica, ya que en general se trata de producciones locales.

En el siglo IX las cerámicas también presentan pastas poco depuradas y frágiles con gran cantidad de desgrasante, similares a las del siglo VIII, hecho que propicia que las coloraciones de las piezas sean muy heterogéneas, ya que en una misma pieza podemos encontrar colores grises, negros y marrones. La tipología más mayoritaria serán las ollas con el borde redondeado de perfil en ese y en menor proporción las de perfil globular; en esta tipología de las ollas desaparecen los bordes biselados, documentados en el siglo VIII y que eran una característica de la cerámica común de la Antigüedad Tardía, y se siguen documentando jarras y cazuelas con el borde redondeado en los yacimientos de Peralada, Can Pelet Ferrer (Llagostera) y Montclús (Sta Maria de Merlès).

La problemática de estas cerámicas de los siglos VIII-IX en Cataluña, surge por que mayoritariamente estamos trabajando con contextos de cerámica común que presentan diferencias mínimas; el grado de depuración de las pastas, diferencias en los bordes de las piezas etc y por el hecho que ni visigodos, ni musulmanes, ni carolingios, producen unas cerámicas propias que abarquen mucho territorio y nos permitan diferenciarlas, de forma clara, de las producciones cerámicas locales en los siglos VIII-IX. Una aportación, que nosotros consideramos que es un reflejo del panorama actual en el estudio de esta cerámica, se hizo en el $6^{\circ}$ Congreso de Cerámica Medieval. Esta destacaba que: "muchas veces, la necesidad de conseguir unas características en la cerámica que está destinada al fuego determina que las piezas sean elaboradas con pastas de desgrasantes grandes que obligan a un modelado a mano o a torneta. Esta práctica no se tiene que interpretar como un atraso tecnológico sino como una manera de adecuarse al proceso de producción. Muchas veces resulta difícil realizar diversas interpretaciones a partir del material cerámico si se desconoce la realidad de lo que se ha encontrado, así como si se desconoce la realidad histórica en que se encuentra el material cerámico" (CAU, J.M et alii 1997), cosa que implica conocer los tipos de establecimientos ${ }^{9}$ y las características históricas que se dan en estos siglos VIII-IX, o sea, en un territorio como es Cataluña actualmente, primero en el final de la Antigüedad Tardía, segundo durante la época islámica y tercero en la época carolingia. Unos aspectos que, generalmente, no se tienen en cuenta a la hora de estudiar estos materiales cerámicos y que provocan serias confusiones en las cronologías que se plantean en la investigación de la alta edad media.

Como he intentado destacar en este artículo, hay elementos suficientes que nos permiten empezar a diferenciar estas cerámicas, pero, también hay que añadir, que, en Cataluña, empezamos a detectar, en algunos casos, que en yacimientos del siglo VIII-IX hay materiales cerámicos similares pero no iguales. Nosotros pensamos que en contexto rural la pervivencia de las producciones cerámicas locales será mayoritaria y supondrá un contrapunto con algunos contextos claramente islámicos. Véase los yacimientos de la Devesa (Besalú), La Torre Mora

9 Para una visión de conjunto de la evolución del poblamiento en Cataluña entre los siglos V-XI ver: MARTí, Ramon (en prensa): "Del fundus a la parrochia. Transformacions del poblament rural en Catalunya durant la transició medieval." III Jornades d'Història i Arqueologia Medieval del Maresme: De Constantí a Carlemay. El pas de l' antiguitat tardana al món medieval al Maresme. Mataró. 
(Arbúcies), El Pla d'Almatà (Balaguer) y el Arxiu Administratiu (Barcelona) que sí que nos permiten una mayor exactitud cronológica, pero solo para casos muy concretos. En la mayoría de yacimientos de época visigoda, islámica y carolingia no hay diferencias tan claras en el material, no hemos identificado en Cataluña una cerámica propiamente visigoda o carolingia, sólo producciones cerámicas locales. Por lo tanto las diferencias en el material en general son mínimas, a veces algunas piezas que sólo se encuentran a nivel microregional o aspectos tipológicos muy concretos. Esto supone un gran problema a la hora de establecer tipologías que nos permitan proponer cronologías suficientemente claras. La única manera de trabajar con estos materiales es a nivel microregional, estudiando yacimientos con cronologías cerradas, de los siglos VIII-IX, que no tengan restos anteriores o posteriores. Esto sólo es posible con campañas exhaustivas de prospección ${ }^{10}$ para localizar estos yacimientos, que, en general, presentan unas dimensiones muy reducidas, aspecto que ha provocado que la investigación de los siglos VIII-IX, en Cataluña y a nivel general en el norte de la Península Ibérica, siga presentado serias lagunas.

\section{BIBLIOGRAFIA}

ALESSANDRI, Patrice (1995): "Ruscino, des wisigoths aux francs", Histoire et archeologie des terres catalanes au Moyen Age, Textes réunis et présentés par Philippe Sénac. Perpignan, 9-48.

BARRASETAS, Maria Eulàlia; Jàrrega, Ramon (1997): La ceràmica trobada al jaciment de la Solana (Cubellas, Garraf). Taula Rodona. Contextos Ceràmics d'Època Romana Tardana i de l'Alta Edat Mitjana (segles IVX).Actes. Badalona, 1996 (Arqueo Mediterrània, 2), Servei de Patrimoni Arquitectònic Local de la Diputació de Barcelona, Museu de Badalona, Universitat de Barcelona. Barcelona, |3|-|52.

BENET, Josep Maria et alii (199|-92): "L'assentament rural del Mas del Catxorro (Benifallet): un exemple de continuitat tardana", Acta Arqueològica de Tarragona Nº4, Reial Societat Arqueològica Tarraconense, Tarragona, 31-44.

BUSQUETS, Francecs; FÂBREGAS, Marta (1998): "L'excavació d'urgència del jaciment de la Devesa (Besalú, La Garrotxa)", IV Jornades d'Arqueologia de les comarques de Girona. Figueres, 149- 167.

BUSQUESTS, Francesc; FÀBREGAS, Marta (2000): "L'arqueologia a Besalú (La Garrotxa) a l'entorn de l' any mil", Actes del congrés Internacional Gerbert d'Orlac i el seu temps: Catalunya i Europa a la fi del primer mileni, Vic-Ripoll 1999, Barcelona, 382-393.

LEEHARDT, Michael et alii (1997): "Céramiques Languedociennes du haut moyen age (Vlle-Xle S.): Essai de synthèse à partir des acquis récents", La céramique médievale en Méditerranée. Actes de be congrés, Aix- en-Provence, |03-1 I0.

I0 En la Universidad Autónoma de Barcelona venimos desarrollando proyectos de estudio documental, de toponímia, de prospección y excavación arqueológica sistemática, desde el año 1995, dirigidos por el Doctor Ramón Martí Castelló, de yacimientos de los siglos VIII-X de Cataluña, Castellón y de Alicante, que están dando resultados. Ver: MARTÍ, Ramon; SELMA, Sergi (I996-97): "La torre emiral de Malpàs (Castellnovo, Alt Palància)". Congrés d'Homenatge a Pere de Palol: d'August a Carlemany. Annals de I'Institut d'Estudis Gironins V.XXXVII, Girona. MARTÍ, R., VILADRICH, M. (2000): "Guissona, origen del bisbat d'Urgell". El Comtat d'Urgell 4, Lleida, 37-66. MARTÍ, R, SELMA, S. (2002): "Fortificaciones y toponimia Omeya en el Este de al-Andalus". Mil anos de fortificaçoes na Península Ibérica e no Magreb (500-1500). Simpósio internacional sobre castelos, Lisboa, 93- I04. MARTí, Ramon (2003): "La defensa del territori durant la transició medieval". I Congrés: els castells medievalss a l' occident de la mediterrànea. Arbúcies, 89I 4. MARTÍ, Ramon (en prensa): "Del fundus a la parrochia. Transformacions del poblament rural en Catalunya durant la transició medieval". III Jornades d'Història i Arqueologia Medieval del Maresme: De Constantí a Carlemay. El pas de l'antiguitat tardana al món medieval al Maresme. Mataró.

CAMPRUBÍ, Josep;MARTÍ, Ramon (en prensa): “Evolució del poblament al Berguedà durant la transició medieval”. Segones jornades d'arqueologia de les comarques de Barcelona, Sant Boi de Llobregat 2003.

FOLCH, Cristian (2003): "Estratègies de conquesta i ocupació islàmica del nord-est de Catalunya". Cuaderns de la Selva N I4. Consell Comarcal de la Selva, pàgs. I39-I54. FOLCH, Cristian; MARTÍ, Ramon (en prensa): "Un edifici del segle IX del vilar de Montclús (Sta Maria de Merlès, Berguedà)", Jornades de Paleontologia i Arqueologia de les comarques de Barcelona. St Boi del Llobregat 2003. FOLCH, Cristian (en prensa): "La ceràmica de l'alta edat mitjana d'un habitatge del vilar de Montclús (Sta Maria de Merlès, Berguedà)". III Jornades d' Història i Arqueologia Medieval del Maresme: De Constantí a Carlemay. El pas de l' antiguitat tardana al món medieval al Maresme. Mataró. FOLCH, Cristian (en prensa): "El poblament al nord-est de Catalunya durant la transició a l'edat mitjana segles (V-XI d.C)". ANNALS de l' Institu d' Estudis Gironins. Girona. FOLCH, Cristian; GIBERT, Jordi; LLINÀS, Joan y MARTÍ, Ramon (2004): "Excavacions arqueològiques a la Torre del Far (Santa Coloma de Farners, La Selva)". Ressó: Revista de Santa Coloma de Farners, 26-27.

GIBERT, Jordi (en prensa): "L'evolució del poblament tardoantic a la depressió penedesenca i els seus marges (segles V-VII)". III Jornades d' Història i Arqueologia Medieval del Maresme: De Constantí a Carlemay. El pas de l' antiguitat tardana al món medieval al Maresme. Mataró. 
CAU, Josep Maria et alii (1997): "La cerámica del nordeste peninsular y las Baleares entre los siglos V-X", La céramique médiévale en Méditérranée. Actes du be congrès, Aix en Provence, 173-192.

COLL, Joan Manel et alii (1995-96): "El Cementiri (Mediona): un jaciment d'època visigòtica al Penedès. Olerdulae (Vilafranca del Penedès), XX-XXI, 1995-1996, 53-67.

COLL, Joan Manel et alii (1997): "Las producciones cerámicas de época visigoda en la Cataluña central (SS.V-VII): Algunas consideraciones técnicas y morfológicas", La céramique médievale en Méditerranée. Actes du be congrés, Aix-en-Provence, 193-197.

COLL, Joan Manel: Roig, J (1997): "Contextos cerámics de l'antiguitat tardana del Vallès". Taula Rodona. Contextos Ceràmics d'Època Romana Tardana i de l'Alta Edat Mitjana (segles IV-X). Badalona, 1996 (Arqueomediterrània, 2), Servei de Patrimoni Arquitectònic Local de la Diputació de Barcelona, Museu de Badalona, Universitat de Barcelona. Barcelona, 37-57.

COLL, Joan Manel; ROIG, Jordi (2000): "Consideracions entorn de la ceràmica de cuina al Vallès: de l'antiguitat tardana a la fi de l'any mill', Actes del Congrés Internacional Gerbert d'Orlac i el seu temps. Catalunya i Europa a la fi del primer mileni. Vic-Ripoll, 457-474.

CURTO, Antoni et alii (1984-85): "Els nivells islàmics en l' excavació de la plaça de Ntra Sra de la Cinta o de l' Olivera de la ciutat de Tortosa (Tarragona)", Actas del primer Congreso de Arqueologia Medieval Española, vol III, Madrid, 99-II2.

ENRICH, Jordi; ENRICH, Joan (1995): Vilaclara de Castellfollit del Boix, Un assentament rural de l'antiguitat tardana. Igualada.

FOLCH, Cristian. (2002): Els Territoris del nord-est de Catalunya a l'inici de l'Edat Mitjana. El poblament als segles VIIIX. Treball de Recerca de Tercer Cicle inèdit. Universitat Autònoma de Bellaterra, Setembre.

FOLCH, Cristian (2003): "Estratègies de conquesta i ocupació islàmica del nord-est de Catalunya", Cuaderns de la Selva No | 4. Consell Comarcal de la Selva, pàgs. I 39- 154.

FOLCH, Cristian; GIBERT, Jordi; LLINÀS, Joan y MARTÍ, Ramon (2004): "Excavacions arqueològiques a la Torre del Far (Santa Coloma de Farners, La Selva)". Ressó: Revista de Santa Coloma de Farners, 26-27.

FOLCH, Cristian; MARTÍ, Ramon (en prensa): "Un edifici del segle IX del vilar de Montclús (Sta Maria de Merlès, Berguedà)", Jornades de Paleontologia i Arqueologia de les comarques de Barcelona. St Boi del Llobregat 2003.

FOLCH, Cristian (en prensa): "La ceràmica de l'alta edat mitjana d'un habitatge del vilar de Montclús (Sta Maria de Merlès, Berguedà)". III jornades d' Història i Arqueologia Medieval del Maresme: De Constantí a Carlemay. El pas de l' antiguitat tardana al món medieval al Maresme. Mataró 2004.
FONT, Gemma et alii (1996): "Intervencions arqueològiques al jaciment de la torre de La Mora (Sant Feliu de Buixalleu, La Selva)". Resultats preliminars, III Jornades d'Arqueologia de les Comarques de Girona. Santa Coloma de Farners, 187-194.

FONT, Gemma et alii (2000): "La torre de la Mora, una construcció d'orígen romà reaprofitada en època alt medieval", V Jornades d'Arqueologia de les Comarques de Girona. Olot, 195-198.

FONT, Gemma et alii (2000): "Torre de la Mora, una fortificació altmedieval en els primers contraforts del Montseny", Actes del Congrés Internacional Gerbert d'Orlac i el seu temps: Catalunya i Europa a la fi del I Mileni. Vic-Ripoll, 409-417.

FUERTES, Maria Carmen (2000): "La evolución de la ceràmica medieval de Cercadilla, Cordoba. Estado de la Cuestión", Anales de Arqueologia Cordobesa XI, Cordoba. Universidad de Cordoba, 217-232

GALVE, Pilar (1988): "Aproximación al estudio de la cerámica de época emiral en la ciudad de Zaragoza", Cesaraugusta 6. Zaragoza, 235-26I.

GARCÍA, Josep Enric et alii (1998): "La gènesi dels espais urbans andalusins (segles VIII-X): Tortosa, Lleida i Balaguer, AAVV: L' Islam i Catalunya. Barcelona. Institut Català de la Mediterrània-Lunwerg Editores-Museu d' Història de Catalunya, I37-165.

GARCÍA, Josep Enric. et alii (2003): "Un context paleoandalusí a l' excavació de l'Arxiu Administariu de BarceIona", II Congrés d' Arqueologia Medieval i Moderna a Catalunya. Sant Cugat del Vallès, 363-380.

GUTIERREZ, Sonia (1996): La cora de tudmir de la antigüedad tardía al mundo islámico. Siglos VI-X. Poblamiento y cultura material. Madrid-Alicante. Casa de Velázquez.

GUTIERREZ, Sonia (1999): "La cerámica emiral de Madînat lyih. (El Tolmo de Minateda, Hellín, Albacete). Una primera aproximación", Arqueología y Territorio Medieval 6. Universidad de Jaén, 7|-|||

LÓPEZ, Alberto et alii (1997): "Ceràmica dels segles IVX procedent de les comarques de Barcelona". Taula Rodona. Contextos Ceràmics d'Època Romana Tardana i de l'Alta Edat Mitjana (segles IV-X). Actes. Badalona, 1996 (Arqueo Mediterrània, 2), Servei de Patrimoni Arquitectònic Local de la Diputació de Barcelona, Museu de Badalona, Universitat de Barcelona. Barcelona, 59-82.

LÓPEZ, Alberto et alii (2003): "Cerámica tardorromana y altomedieval en la provincia de Barcelona. Siglos VII-X". CABALLERO, Luis; MATEOS, Pedro y RETUERCE, Manuel (edts.) (2003). Cerámicas tardorromanas y altomedievales en la Península Ibérica. Anejos de AespA XXVIII, Mérida, 4 I-65.

LLINÀS, Joan (1997): "La Excavación de la Carretera de San Martín de Ampurias (Gerona): Un ejemplo de la evolución de los contextos cerámicos durante la Antigüedad tardía en el litoral catalán", Archivo Español de Arqueología 70, Madrid, 149-169. 
LLINÀS, Joan et alii ( 1999): "La peralada ibèrica i medieval segons l'arqueologia". Les excavacions de 1989 a 1995 , Monografies Empordaneses N ${ }^{\circ}$ 4. Institut d'Estudis Empordanesos, Figueres 1999.

MARTí, Ramon; SELMA, Sergi (1996-97): "La torre emiral de Malpàs (Castellnovo, Alt Palància)", Congrés d'Homenatge a Pere de Palol: d'August a Carlemany. Annals de I'Institut d'Estudis Gironins V.XXXVII, Girona.

MARTÍ, R y SELMA, S (2000): "Fortificaciones y toponímia Omeya en el este de al-Andalus". Simposio Internacional Sobre Castelos, Palmela 2000.

MARTÍ, Ramon. (2003): "La defensa del territori durant la transició medieval", I Congrés: els castell medievals a l' occident de la mediterrànea. Arbúcies, 89-1 |4.

MARTÍ, Ramon (en prensa): Del fundus a la parrochia. transformacions del poblament rural en Catalunya durant la transició medieval. III Jornades d'Història i Arqueologia Medieval del Maresme: De Constantí a Carlemay. El pas de l' antiguitat tardana al món medieval al Maresme. Mataró.

PALOL, Pere (1989): Bovalar: Un poblat d'època visigòtica. Guia. Lleida
PALOMO, Vicenç et alii (2000): "Treballs arqueològics del condicionament de la carretera Gl-68I LLagosteraTossa de Mar del P.K 0+000 al 7+500 (Gironés, la Selva)", $\checkmark$ Jornades d'Arqueologia de les Comarques de Girona. p.277280. Olot 12 y 13 de mayo de 2000.

PALOMO, Vicenç et alii (2003), "Can Pelet Ferrer (Llagostera, Gironès): un assentament agrícola alt-medieval", II Congrés d' Arqueologia Medieval i Moderna a Catalunya. Sant Cugat del Vallès, 476-480.

PUIG, Anna Maria (1998): "El jaciment de RHODE a la fi de l'antiguitat tardana. Els contextos del segle VII d.C a la ciutadella de Roses (Alt Empordà, Girona)". Pirenae $N^{\circ}$ 29. UB. Barcelona, |7|-|9|.

RIU, Eduard (2000): "La ceràmica de la Mediterrània nordoccidental en els segles VIII-IX. Catalunya, el País Valencià i les Balears entre I' Imperi carolingi i l' al-Àndalus". Catalunya a l'època carolingia. Art i cultura abans del romànic (Segles IX-X). Barcelona, 259-263.

ROIG, Jordi; COLL, Joan Manel (1994): Els Visigots al Vallès. Treball becat per la Caixa de Sabadell, Sabadell. 


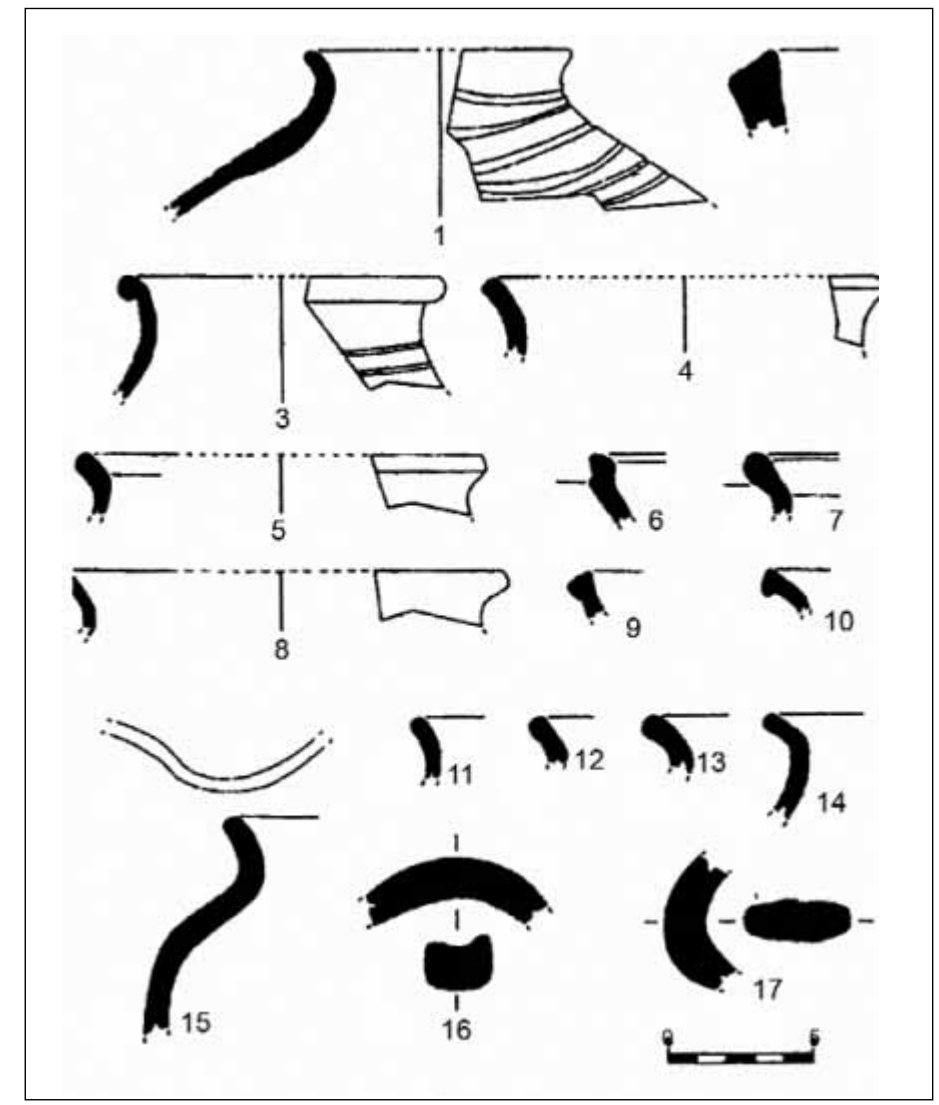

Fig. I. La Devesa (Besalú). Busquets, F. et alii, 1998

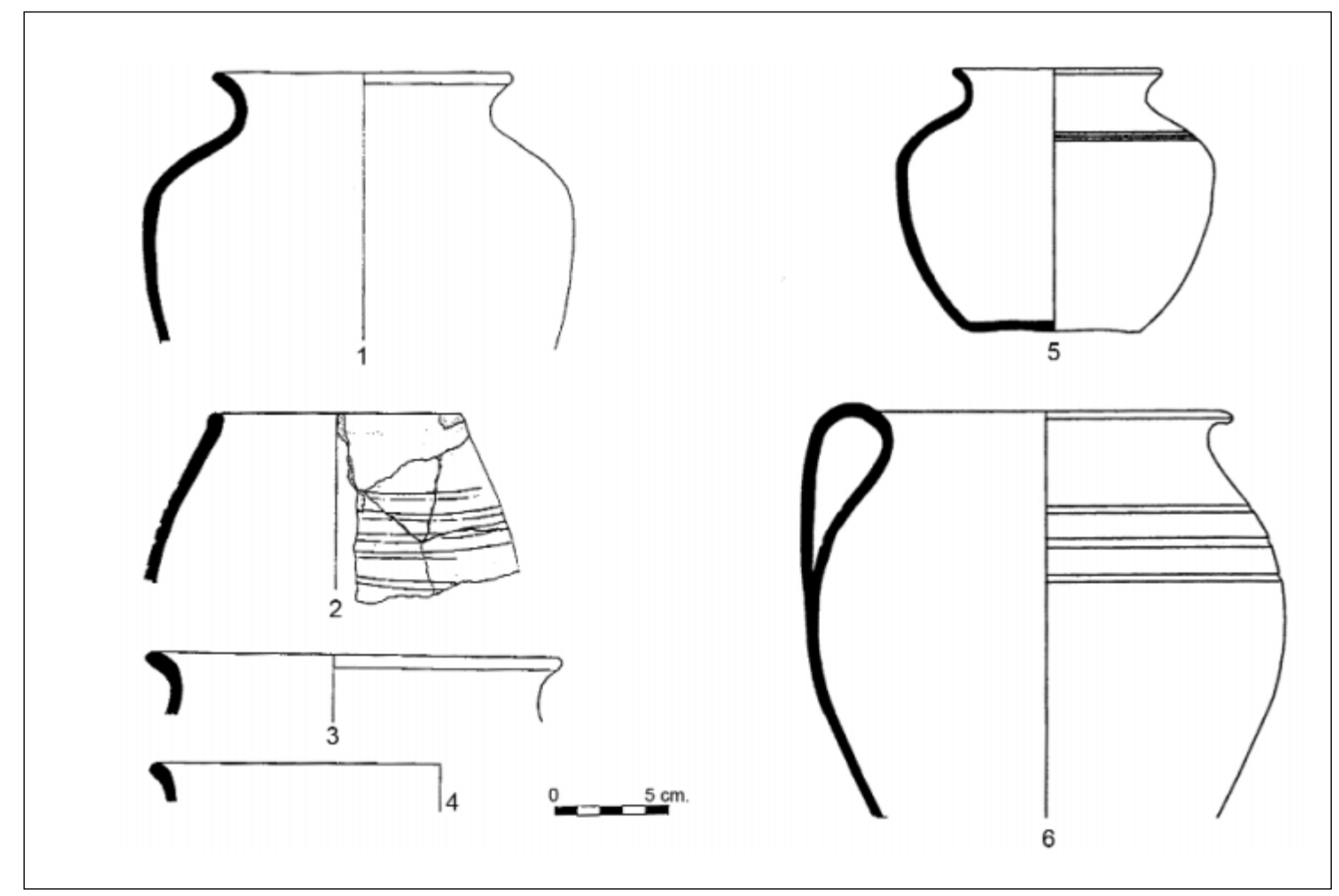

Fig. 2. La Torre Mora (San Feliu de Buixalleu). Font, G. et alii, 1996 y 2000 


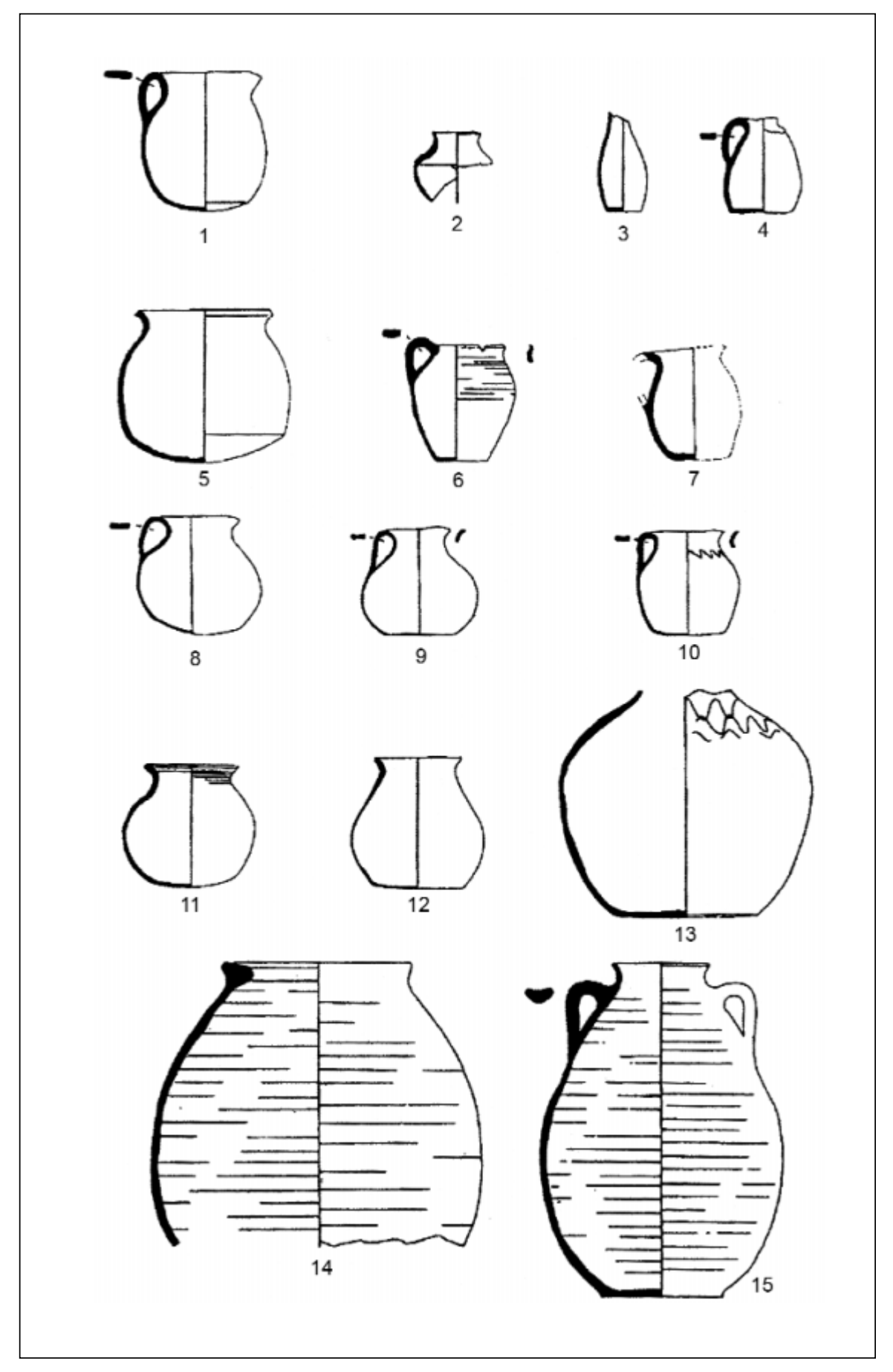

Fig. 3. Bovalar (Seròs). Cau, J. et alii, 1996 


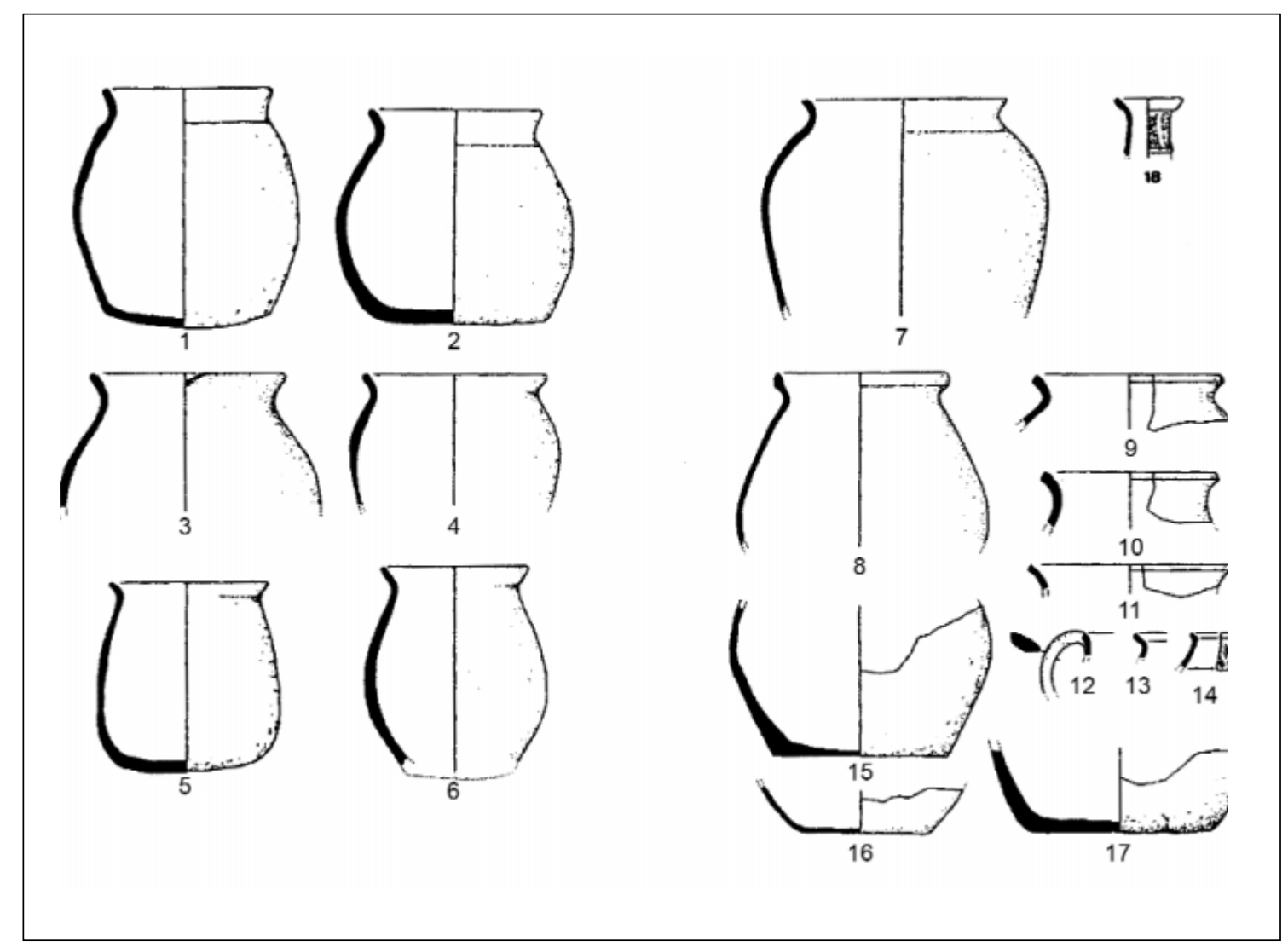

Fig. 4. Aiguacuit (Terrassa). Coll, J. M. et alii, 1997

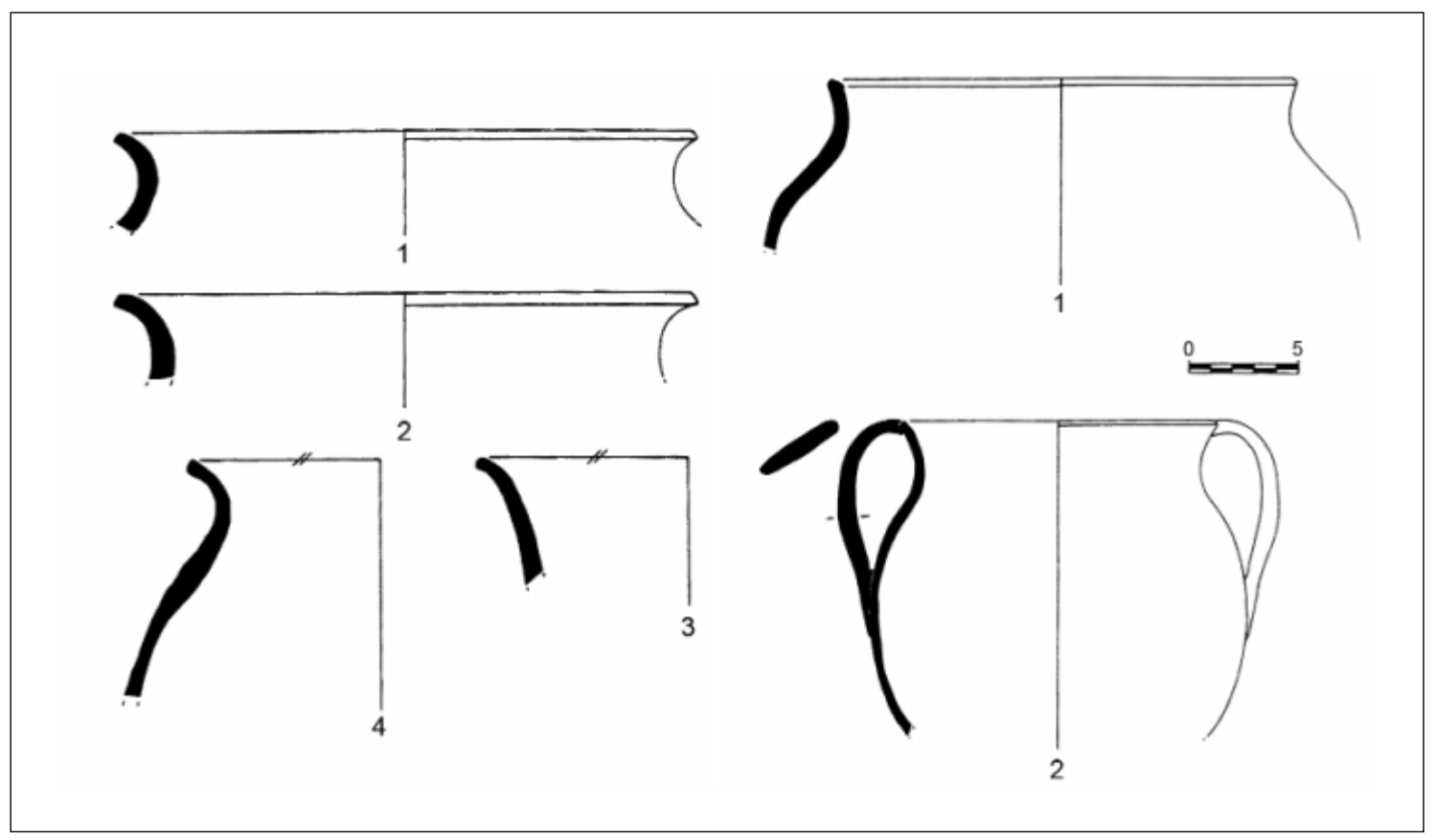

Fig. 5. Mas de Catxorro (Benifallet). Benet, J. M. et alii, 1991-1992 


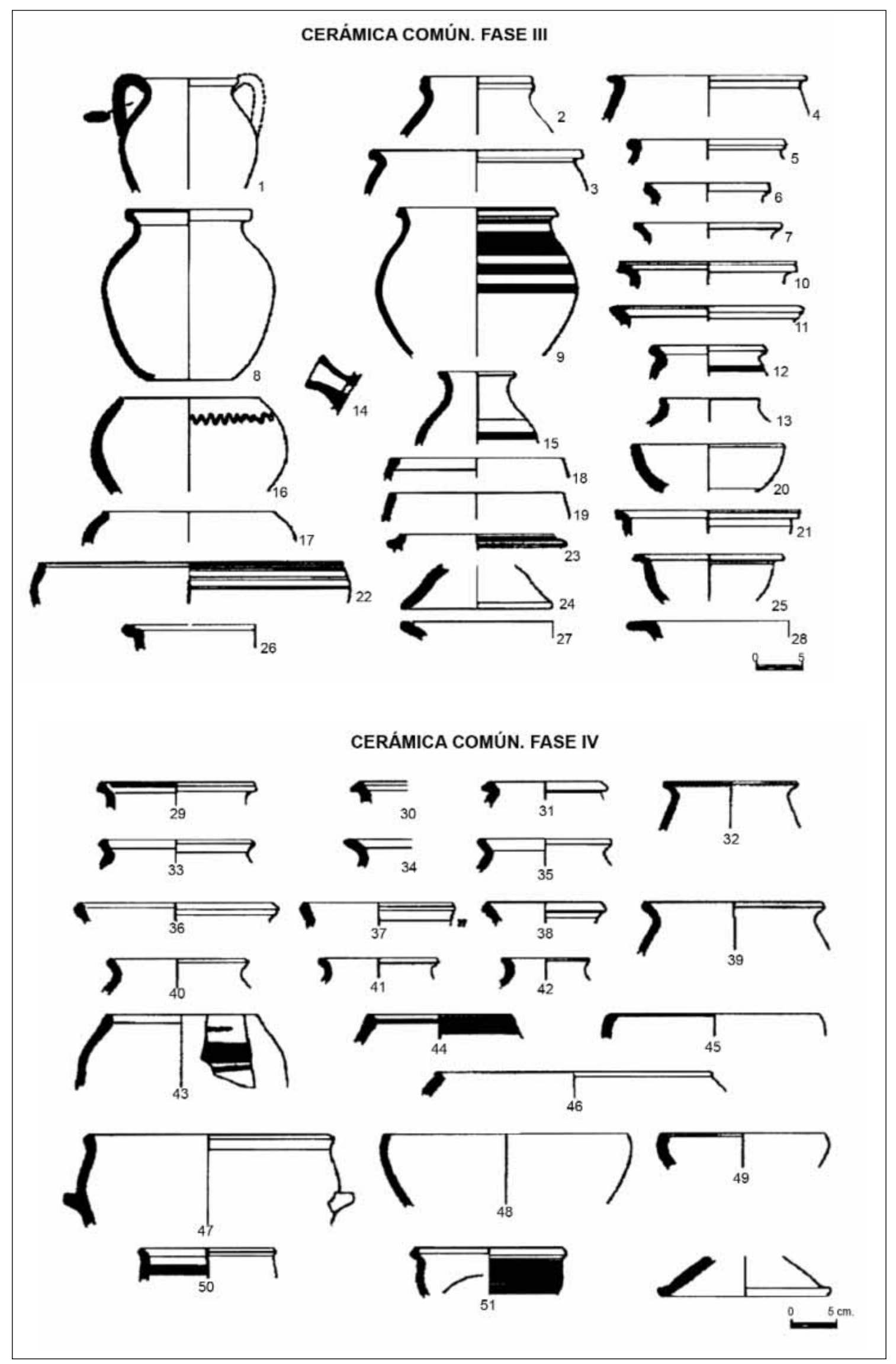

Fig. 6. Arxiu Administratiu (Barcelona). García, J. et alii, 2002 


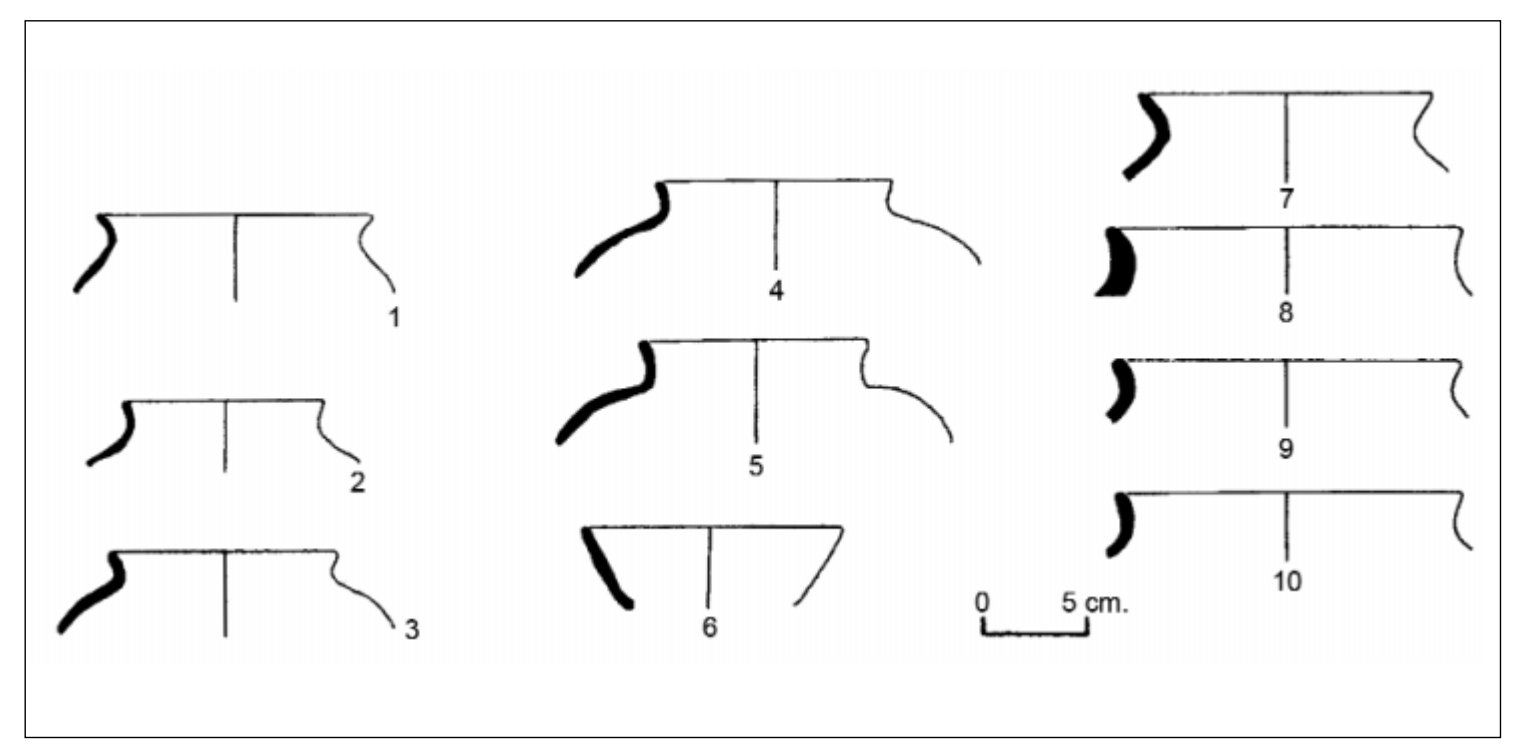

Fig. 7. Monclús (Santa María de Merlès). Folch, C., 2005

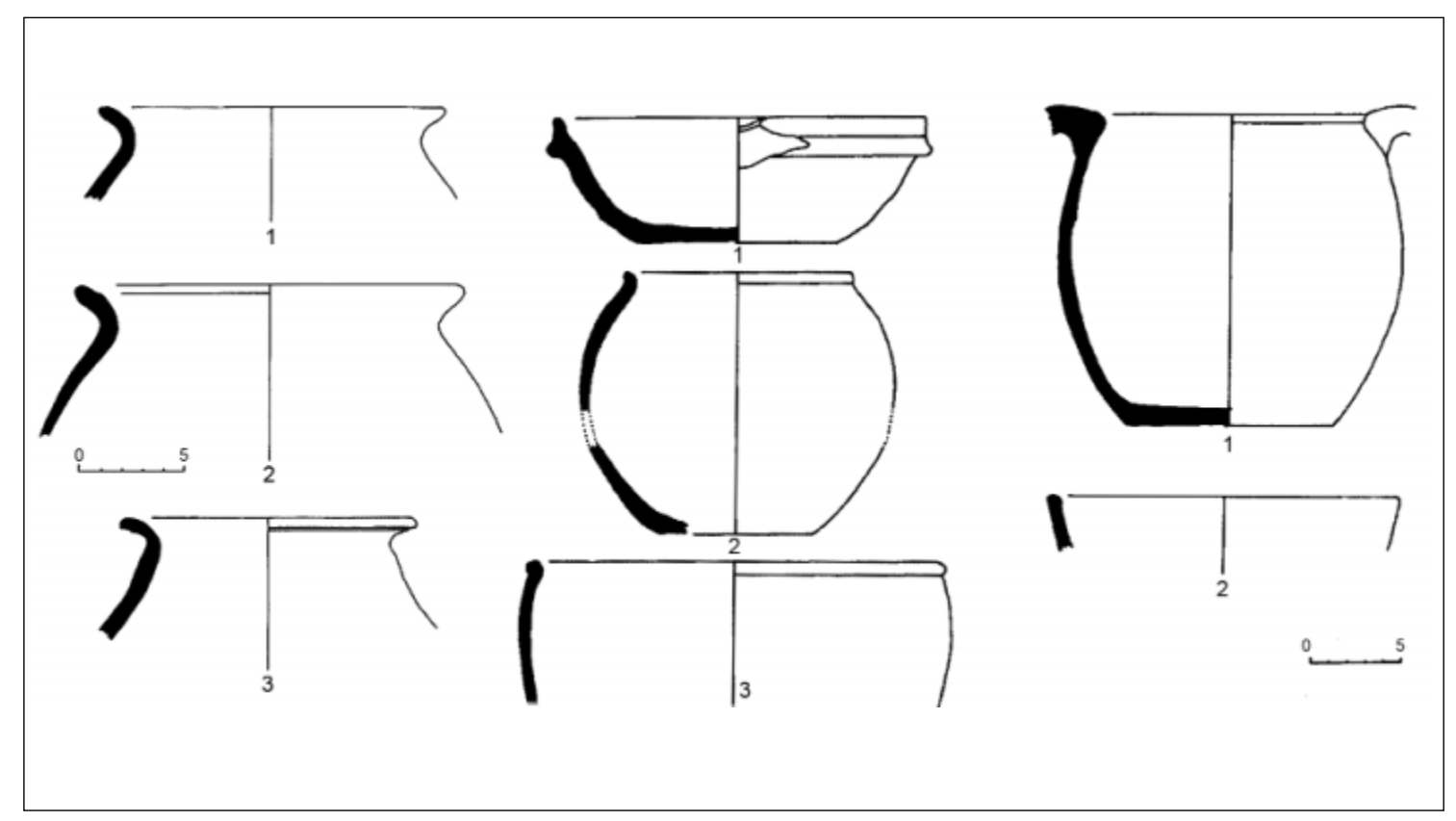

Fig. 8. Can Pelet Ferrer (Llagostera). Palomo, V. et alii, 2000 


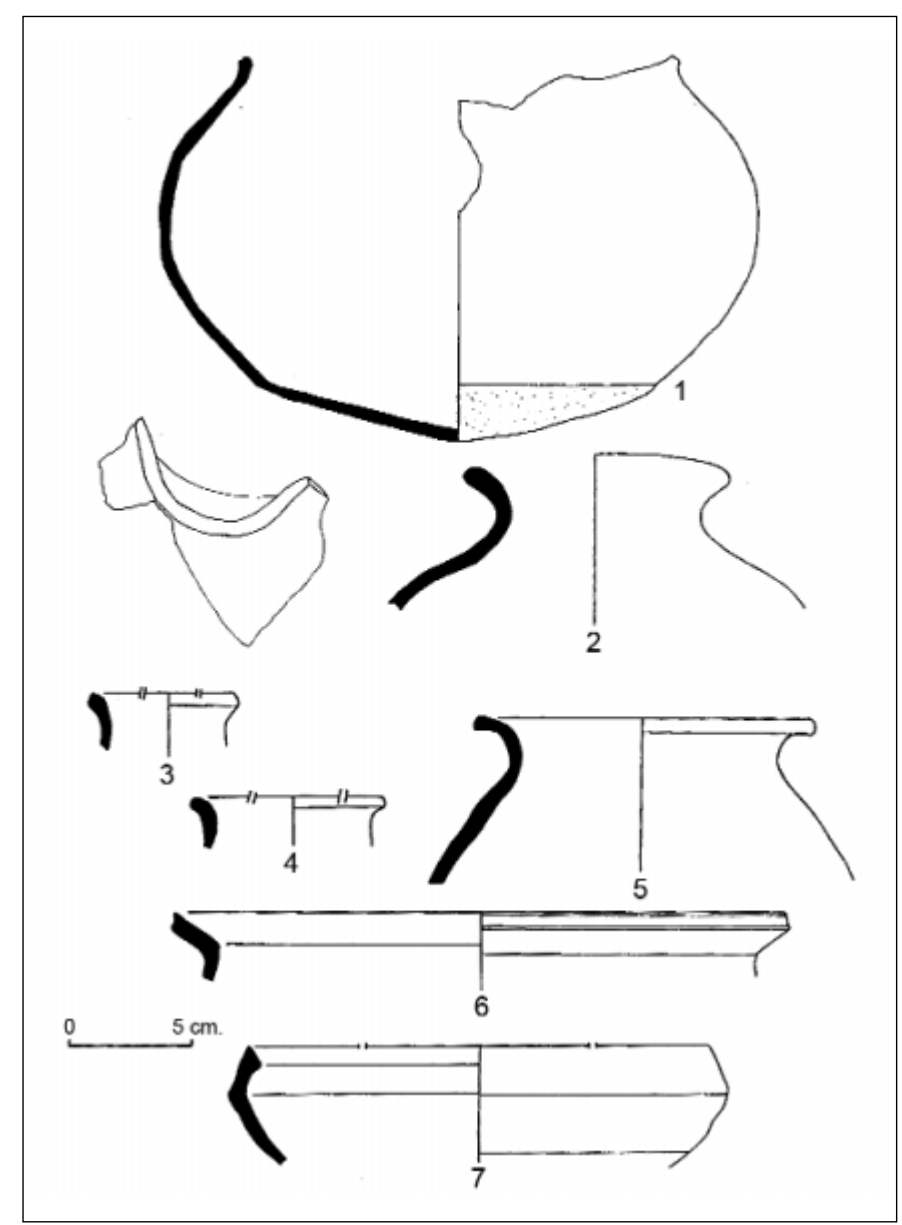

Fig. 9. Peralada. Llinàs, J. et alii, 1999

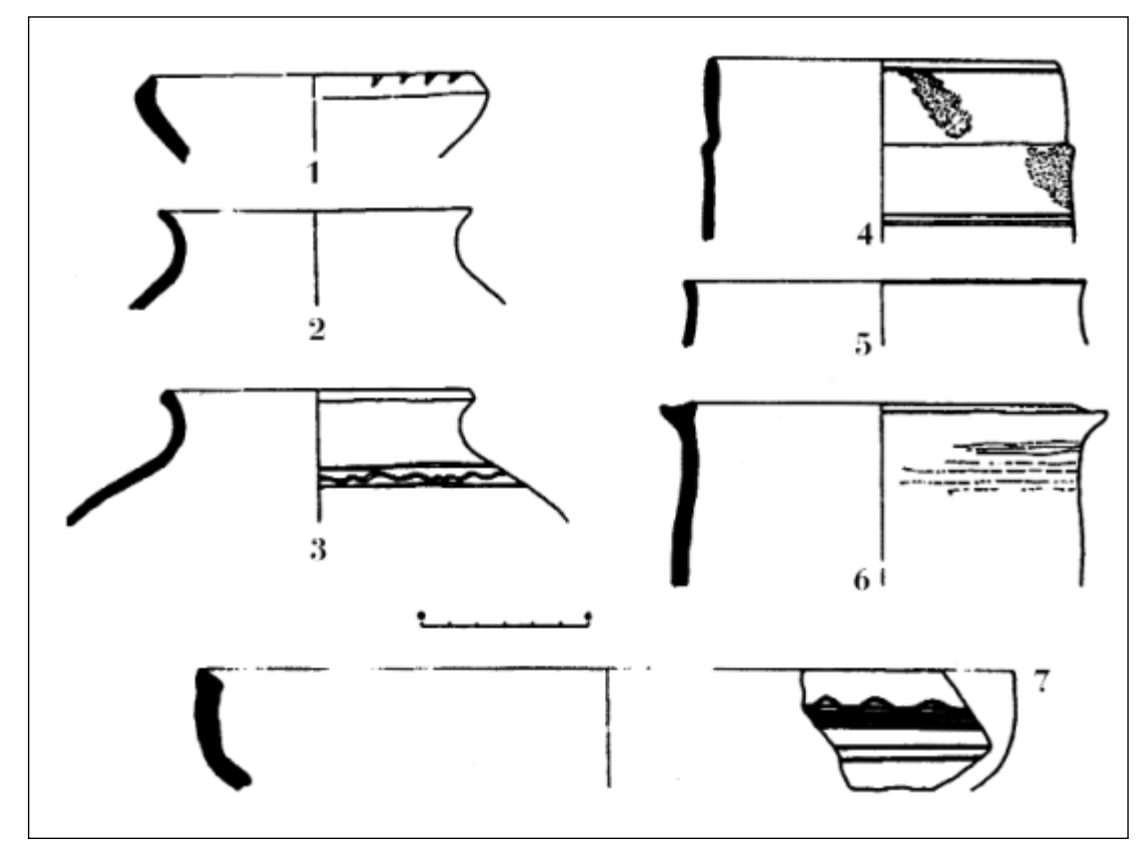

Fig. 10. Pla D'Almatà (Balaguer). Cau, J. et alii, 1997 